\title{
Impact of Information on Food Stocking during Early Period of COVID-19 Outbreak: Survey Exploration between Canada and US Consumers
}

\author{
Yuanfang $\operatorname{Lin}^{1}$, Xuezhu Wang ${ }^{1}, \&$ Tirtha Dhar ${ }^{1}$ \\ ${ }^{1}$ Gordon S. Lang School of Business and Economics, University of Guelph, Guelph, Canada \\ Correspondence: Yuanfang Lin, Gordon S. Lang School of Business and Economics, University of Guelph, \\ Guelph, ON., N1G 2W1, Canada.
}

Received: December 11, 2020

Accepted: January 11, 2020

Online Published: January 21, 2020

doi:10.5539/ibr.v14n2p72

URL: https://doi.org/10.5539/ibr.v14n2p72

\begin{abstract}
We summarize the exploration results from a survey study that asks Canada and U.S. consumers questions related to their acquisition and processing of information related to the COVID-19 pandemic, situation assessment at the beginning of outbreak, as well as food shopping and stocking behavior during the lockdown. Our analyses identified unique factors influencing consumers' situation assessment and stockpiling decisions that are going along with the emerging social and cultural trends over the past two decades. These include the wide reach of internet-based media, multiple sources of information in terms of different media types, media languages as well as communication across country borders towards an individual's immigration and other ethnicity background. Information obtained from social media sources is found to have statistically different impact on the initial situation assessment between Canada and U.S. customers. But learning COVID-19 news from non-English media source significantly increases the seriousness perception of consumers from both countries. Information acquisition from multiple language sources also makes a Canadian customer more likely to stockpiling food items. Consumers' food stocking behavior from both countries are under the influence of societal and economic factors such as job security. Findings from our research contribute to the ongoing global efforts in mitigating COVID-19's negative impact by generating effective policy and strategic recommendations for government and business communities to implement collaborative and constructive actions under the global pandemic.
\end{abstract}

Keywords: COVID-19, ethnic diversity, information sources, media language, stockpiling

\section{Introduction}

\subsection{Background}

The impact of COVID-19 pandemic and the lockdown which had been taking place across the globe were unprecedentedly striking for the society worldwide. Almost all businesses have to adapt and adjust their networks of product ordering, stocking, allocation and distribution due to the fluctuation of demand which are closely linked to the global economy network under the pandemic. The primary focus of this research paper is on North American consumers' stockpiling behavior during COVID-19 and the exploration and identification of unique informational and social drivers which were different from previous outbreaks within this century. Extensive research in business and economics have classified consumer stockpiling as an unconventional loss-avoidance shopping behavior under environmental stress/ uncertainty (Helsen \& Schmittlein, 1992; Azadegan, Patel, Zangoueinezhad, \& Linderman, 2013; Barello, 2014). It was certainly also the case under the current COVID-19 pandemic. First weeks of the COVID-19 lockdown in many cities of Canada have witnessed striking themes as food and other products flew off store shelves as fast as (or even faster than) they could be stacked (Bogart, 2020). Statistics Canada has recorded percentage increases in sales for a wide range of food products for the week ending in mid-March 2020 in comparison to the average level in 2019, with some increases (e.g. frozen fruits, frozen vegetable) over $120 \%$ !

\subsection{Research Objectives}

Instead of further confirming the existence of consumer stockpiling, we aim to empirically explore and identify unique driving forces behind such phenomenon under COVID-19 in comparison to the period of past two 
pandemic outbreaks (SARS, HIN1) the human society had experienced since the beginning of this century. Those forces could be corresponding to the emerging social-economic trends developed during the same time period (the past two decades). The specific research questions we are investigating include: How did consumers acquire and process information related to COVID-19 at the beginning of outbreak? How would such information process influence consumers' shopping behaviour under lock down? What kind of consumers are more likely to stockpile? Unlike existing studies (Sterman \& Dogan, 2015) on consumer stockpiling and business operation under short-term environmental stresses (e.g. hurricane), the widespread outbreak of COVID-19 may lead to global shortages of product supply on a much larger scale, making it increasingly more difficult for retailers to satisfy demands using conventional measures such as increasing order from suppliers or shifting inventory around networks. It calls for a systematic adjustment in both the information communication strategy and marketing distribution channels to combat the negative impact on society due to the COVID-19 pandemic. Answers to our research questions would be highly valuable to policy makers and business managers to implement collaborative and constructive actions to maintain the social welfare under pandemic. Our study thus contributes to the global efforts in mitigating COVID-19's negative impact from social, economy and policy perspectives.

\subsection{Overview of Research Findings}

Using results from a multi-round survey administered on Qualtrics survey platform towards Canadian and U.S. participants recruited through Amazon MTurk cloud service, we present empirical evidences that the growing reach of online media over the past two decades are having much more significant influences on consumers' initial assessment regarding the seriousness of COVID-19 pandemic in comparison to traditional media types. The growing demographic diversification in the North American society also generates potentially multiple sources of information acquisition and sharing about COVID-19 which include but are not limited to various media sources, different media languages, and communication within and across the residential country borders. Acquiring and exchanging COVID-19 news via multiple sources tend to let a consumer have an early perception of a more serious pandemic outbreak which could in turn drive the food stockpiling decision. Noticeable differences were found between U.S. and Canadian residents when it comes to the initial situation assessment at the beginning of outbreak. As it got past the initial outbreak, consumers' decision to stockpiling during the lockdown period is found to be driven less by information sources, but rather due to the choice of shopping mode (online vs offline), concerns over pandemic related social issues (e.g. job security) and specific demographic characteristics (e.g. gender, ethnicity).

\section{Literature Review}

This paper is primarily connected with economics and business studies on the drivers and determinants of consumers shopping and stockpiling behaviour under various market and situational conditions.

\subsection{Consumer Food Stockpiling under General Economic Conditions}

Price promotion has long been identified as a common drive for consumers' stockpiling behaviour. In particular, a low promotion environment tends to attract consumers to stockpile (Bell, Chiang, \& Padmanabhan, 1999; Gupta, 1988; Helsen \& Schmittlein, 1992) while seeking optimal solution to the household inventory (Assuncao \& Meyer, 1993; Boizot, Robin, \& Visser, 2001; Hendel \& Nevo, 2006). In the context of retail operations management, consumer stockpiling behaviour has been identified as heterogeneous segments' responses under the high-low (HILO) pricing environment (Blattberg, Eppen, \& Lieberman, 1981; Breiter \& Huchzermeier, 2015). Stockpiling consumers value monetary savings over convenience and are willing to stockpile their inventory, postpone purchases, or buy lower quantities, depending on the promotion available facing price variability in a HILO environment (Ho, Tang, \& Bell, 1998). Studying how consumers respond to promotions through stockpiling has been found to benefit retailers and manufacturers by information sharing (Iyer \& Ye, 2000) and the reduction of production planning costs (Huchzermeier, Iyer, \& Freiheit, 2002).

\subsection{Consumer Food Stockpiling under Environmental Stress}

Extensive researches have been investigating consumer stockpiling behaviour under various dimensions of environmental uncertainty originated from financial situation, economic event, and other external factors such as natural disaster (Wernerfelt \& Karani, 1987). Environmental changes due to financial and economic events have been noticeably found to precipitate significant stress on consumers to engage in stockpiling behaviour (Hobson et al., 1998). Tokar, Aloysius, Williams, and Waller (2014) finds the bias toward over-ordering relative to optimal orders, while Sterman and Dogan (2015) study hoarding and phantom ordering under anticipated demand shock. Both studies indicate that environmental stress stimulates the impulse to stockpile in preparation for uncertain outcomes (Sweeny \& Shepperd, 2007). Behaviour research has identified the dilemma that facing financial stress, 
consumers may be incentivized to stockpile to take advantage of promotional prices; however, financial resources may limit consumers' ability to stockpile (Bendoly \& Hur, 2007).

There is another stream of research on consumer irrational stockpiling, hoarding or panic buying behaviour associated with major natural disasters and humanitarian crisis (hurricane, earthquake) where many consumers buy unusually large amounts of product to avoid possible future shortage due to supply disruption. Unlike store or brand promotion-triggered stockpiling, disaster triggered stockpiling behaviour contains more irrational factors and can be treated as an unconventional inventory accumulation action for reducing potential losses (Hendricks, Jacobs, \& Singhal, 2019; Snyder et al., 2015). Fear of the unknown is reflected in panic buying behaviours as consumers channel their lack of knowledge about crises into behaviours perceived as comforting, providing security or that alleviate stress (Elmore, 2017). With limited information and time for thinking and judging the situation during disasters, the fear of commodity scarcity becomes contagious and the distorted facts and exaggerated misinformation will increase stockpiling behaviour and purchase acceleration (Zheng, Shou, \& Yang, 2020). Panic buying often leads to large quantities of necessities and medical supplies being purchased from vendors, and vastly limiting or even eliminating availability such that individuals and vulnerable groups, including the elderly or poor, are prevented from accessing them as they would normally do (Besson, 2020). As there are no broadly researched modern pandemics outside of SARS in 2003, which was fairly localised in its presentation, research on COVID-19 will be formative for understanding and perhaps anticipating the future of shock and crisis research (Loxton et al., 2020). Research conducted by Yuen, Wang, Ma, \& Li (2020) in response to the coronavirus established four key factors causing panic buying: (1) perception, (2) fear of the unknown, (3) coping behaviour and (4) social psychology.

\subsection{Information-Related Drivers behind Consumer Food Stockpiling under COVID-19}

Behavioural economics illustrates the effect of an information cascade, whereby consumers within a network are influenced by the behaviours and decisions of others (Easley \& Kleinberg, 2010). With limited information and time for thinking and judging the situation during disasters, the fear of commodity scarcity becomes contagious and spreads expeditiously over media channels (e.g., social media, TV, radio, newspaper). Distorted facts and exaggerated misinformation will increase stockpiling behaviour and purchase acceleration and deteriorate the situation (Chen et al., 2020). Such information-related impact on consumers' food purchase and stocking behaviour is expected to become more prominent considering the evolution of media development and consumption in North America during the past two decades (2000 - 2020), in particular, compared with the time of SARS outbreak (2003) and H1N1 (2011), which were the past two pandemic outbreaks the human society had experienced since the beginning of this century.

\subsection{Research Contribution}

This paper focuses on exploring factors influencing COVID-19 information acquisition, process and exchange which are closely tied to consumers' demographic and ethnic background, as well as the emerging social trends in the past two decades. To our best knowledge, there has not been study from such angle to investigate the informational impact on consumers' purchasing and stockpiling behaviour during COVID-19 pandemic. We formally develop our research hypothesis in the next section.

\section{Conceptual Framework}

The overall conceptual framework of our study is illustrated by Figure 1 which is followed by detailed discussion of each research hypothesis. 


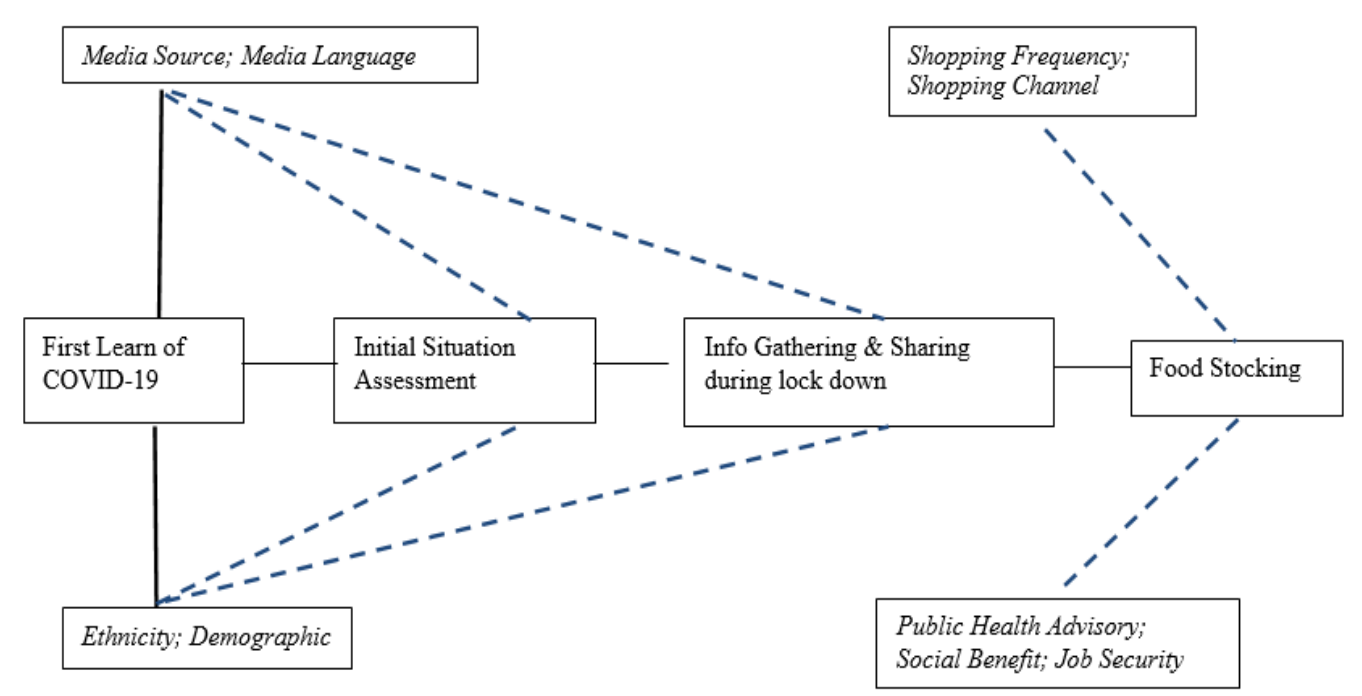

Figure 1. Conceptual Framework

\subsection{Impact of Media Types}

Figure 2 displays the reach evolution of different media types in Canada from 2001 to 2019. By 2019, internet media has achieved near 100\% reach in Canada, while the reach of traditional media including newspaper and magazine have experienced significant decline (below $50 \%$ by 2019) in comparison to the periods during the past two outbreak in this century. Similar observation can be made in the U.S. (Figure 3) where internet users reached 312 million in 2019, which was up from nearly 287 million in 2017 and represented over $95 \%$ of total population (328.2 million according to statista.com). Marketing research has found the increase of "search online, purchase offline" pattern of consumer shopping behavior in a wide variety of markets and product categories (Zhuang, Leszczyc, \& Lin, 2018).

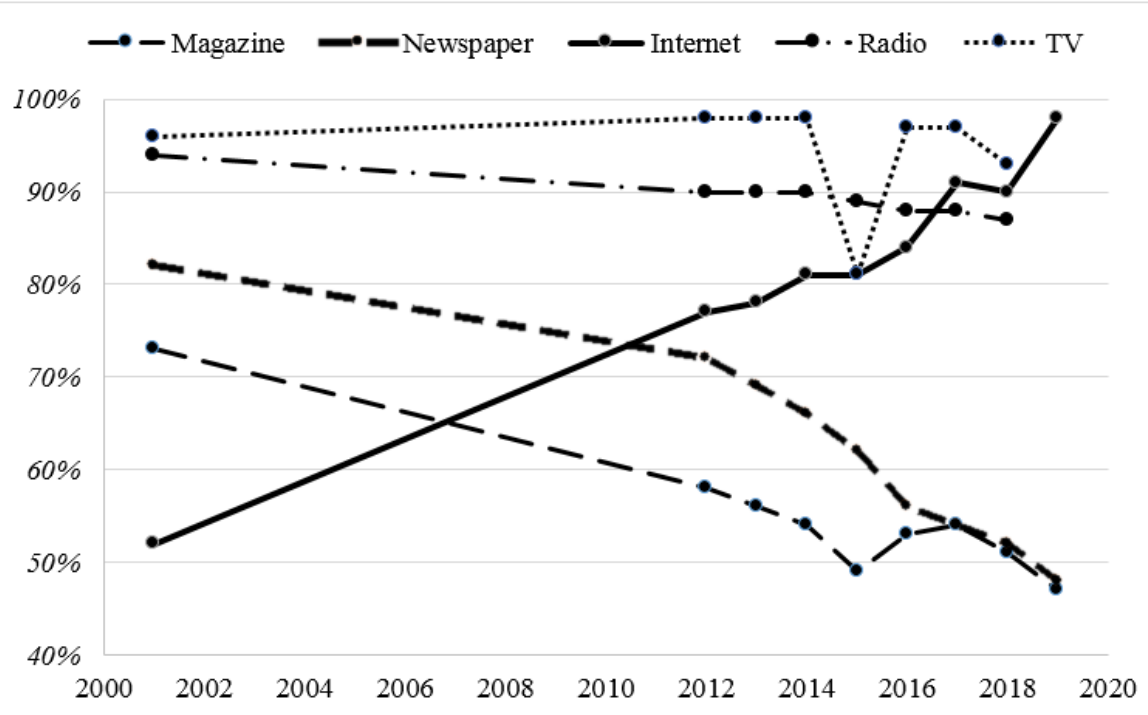

Figure 2. Weekly reach of selected media in Canada

Note: Figure 2 was generated by the authors using raw data $2001-2019$ from IAB Canada. 


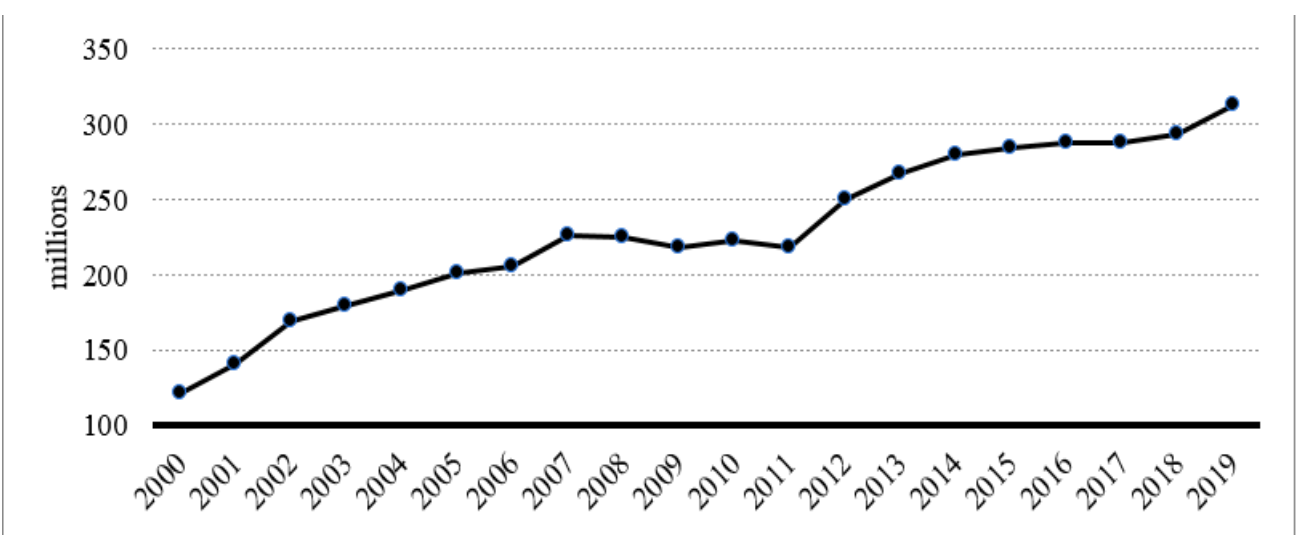

Figure 3. Number of internet users in the United States from 2000 to 2019 (Internet World Stats)

We believe that the rise and decline of those different media types will in turn affect how consumers obtain COVID-19 related information which would have been different from decades ago. Formally, we state our first hypothesis as:

Hypothesis \#1: Information obtained via online media source has greater impact on consumers' initial situation assessment regarding COVID-19 (in comparison to the traditional media types).

\subsection{Impact of Media Languages}

Another trend that was developing along the same time span $(2000-2019)$ is the growing number of immigrants in both countries with the upward trend more prominent for Canada as indicated by Figure 4. Along with the growing number, the latest census in Canada (2016) also indicates high retention rate of immigrant mother tongues at home as summarized by Figure 5. We can interpret Figures 4 \& 5 as that nearly 80\% (El-Assal, 2020) of Canadians could be speaking mother tongues at home which are different from English or French as the country's official language especially at work. Noticeably Canadians across the country have been experiencing lock down of various forms during the majority time of the past (nearly) half year (March - September, 2020), which makes a quite blurry line between gathering information from home or from work. A similar usage pattern of mother language by immigrants at home was observed in the U.S. from a recent survey on immigration trends and language conducted by Pew Research Center (Scamman, 2019).

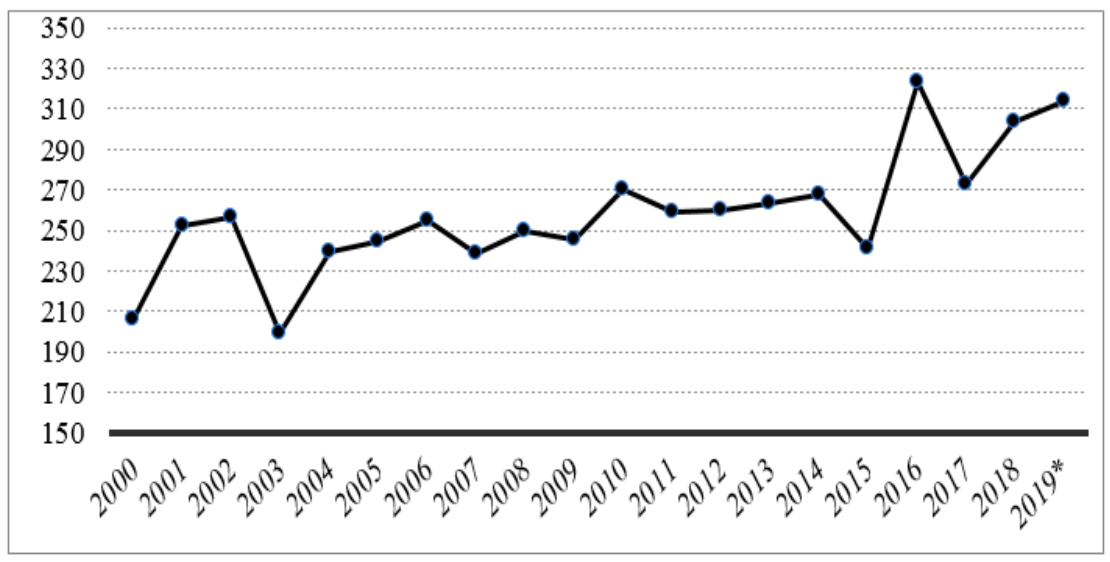

Figure 4. Number of immigrants (in 1,000s) in Canada from 2001 - 2019 (Statista.com) 


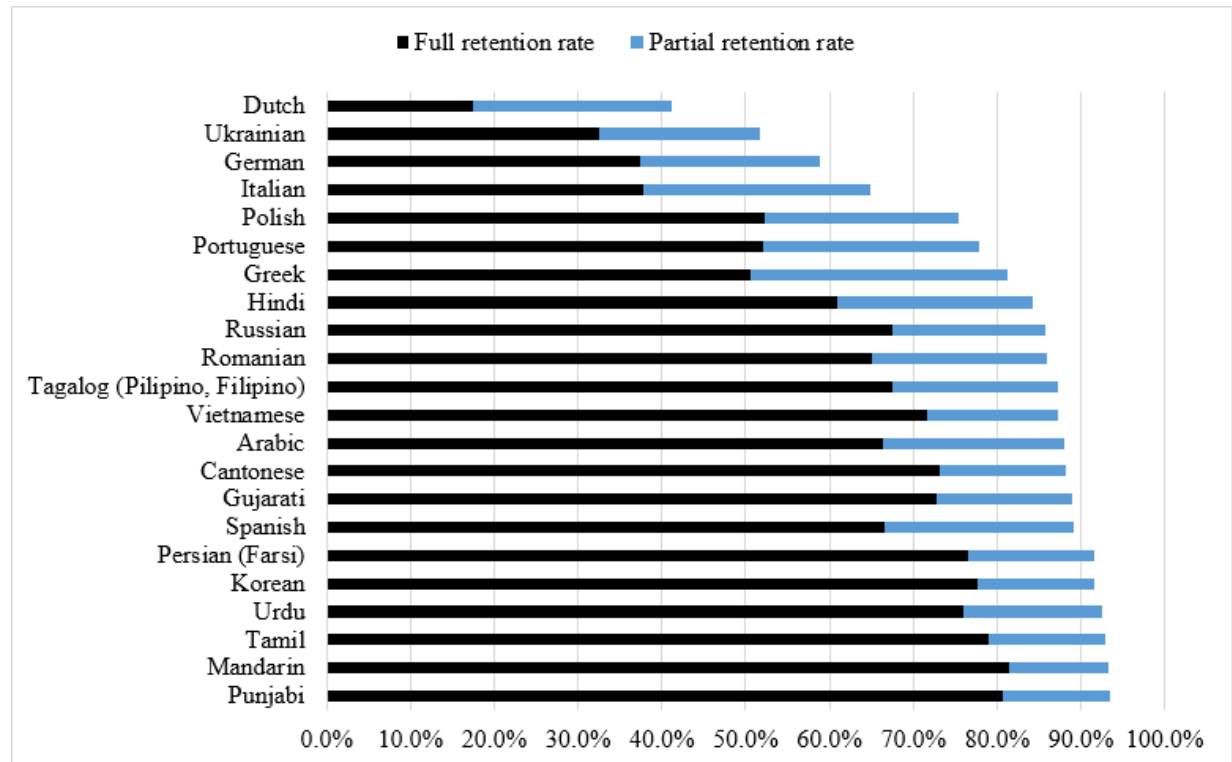

Figure 5. Full or partial retention rate for the 22 main immigrant mother tongues in Canada (Census 2016)

The ethnicity and language diversity would clearly influence consumers' preferred language of media consumption (see Figure 6 for Canadian consumers). On the flip side, the multiple media language sources may also add to government authority's concern with regards to the spread of fake news or misleading information about COVID-19, which was labelled by World Health Organization (WHO) as "infodemic" (Charlton, 2020). We now formally state the second hypothesis for empirical investigation:

Hypothesis \#2: Information from multiple language sources would increase the level of seriousness in consumers' initial COVID-19 situation assessment.

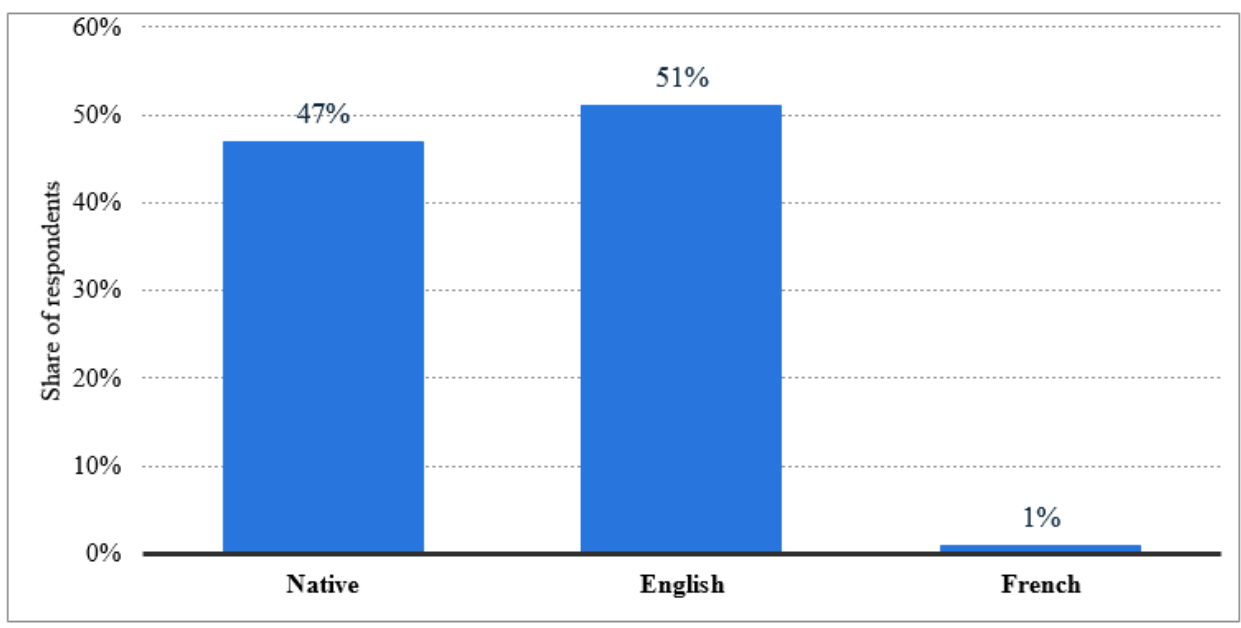

Figure 6. Preferred language of media consumption among immigrants to Canada (Yahoo Canada, October 2014)

\subsection{Impact of Information Exchange}

The outbreak and lockdown allowed consumers to spend more time online for various activities as found out in the McKinsey COVID-19 Consumer survey of over 6000 participants during March 27-29, 2020 (Figure 7). Meanwhile the unique character of ethnicity and mother-language diversity also created additional channel of information exchange. One of the co-authors personally experienced the following scenario: around January 2020, he started forwarding his parents (at that time resided outside Canada) media reports in English covering 
the COVID-19 outbreak at his parents' country of residence, urging them to take necessary precautionary measures. Turning the clock to March 2020, it was the turn of his parents who were busy forwarding him media reports (in their mother language) about the outbreak in Canada with similar warning message of necessary stocking in preparation for lock down. We suspect that given the huge proportion of immigrant populations in North America as discussed earlier, such pattern of multiple information exchange would play an important role in customers' stockpiling decision during the pandemic outbreak. Formally, we state the third hypothesis as:

Hypothesis \#3: Information exchange from multiple sources especially those outside the country of residences would increase consumer's propensity of food stockpiling.

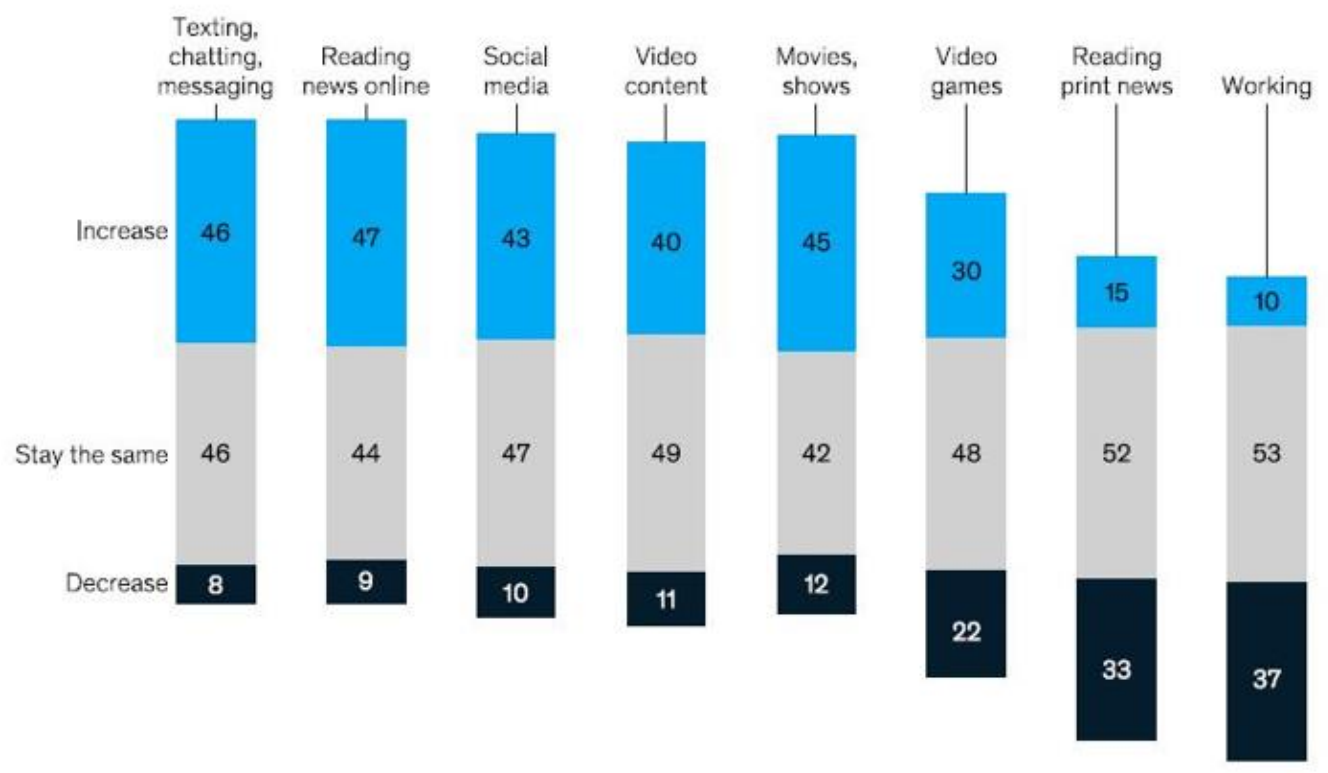

Figure 7. Change in time spent on selected activities during pandemic (\% of respondents)

\subsection{Other Societal Impacts}

Finally, the COVID-19 pandemic has indeed stirred up a wide range of social-economic issues/ concerns including but are not limited to social distancing, border closure, reduced international supply cargos, job security, and social benefits (Shapira, Coco, \& Sorbara, 2020). Our final hypothesis suggests that how concerned a consumer is regarding the COVID-19 related social-economic issues would contribute to the psychological drives behind the unconventional stockpiling under the pandemic.

Hypothesis \#4: A consumer who is more concerned about COVID-19 related social-economic issues is more likely to engage in food stockpiling.

\section{Research Methodology}

The analyses presented in this paper are based on primary data collected from two rounds of consumer survey study. The purpose of study is to investigate consumer information acquisition and exchange regarding COVID-19 pandemic, the impacts on initial perception of the outbreak and the stockpiling decision during grocery purchase. The surveys are administered online via Qualtrics platform and the participants are anonymously recruited from Amazon Mechanic Turk (MTurk) crowdsourcing marketplace. All respondents are required to be US or Canadian residents, fluent in English, and 18 or older.

\subsection{Online Survey 1}

The first round of survey was conducted in June 2020. The survey period is of great interest because for our primary geographic area of research focus, North America, initial outbreak and lock down of various forms typically occurred around mid - March of 2020 as summarized by Table 1. As time approached the end of June, most provinces or territories in Canada have been experiencing outbreak and lockdown for nearly 3 months and there had been discussions regarding various plans of re-opening (Rocca, 2020). Survey participants during this period are expected to have more time and more stable mindset to recall experiences at the beginning or early period of outbreak and to provide more reliable survey responses. 
Table 1. Provincial/ Territorial lock down time due to COVID-19 (Canada)

\begin{tabular}{|cc|}
\hline Province/Territory & State of Emergency Declared \\
\hline Quebec & $12-\mathrm{Mar}$ \\
\hline Prince Edward Island & $16-\mathrm{Mar}$ \\
\hline Alberta & $17-\mathrm{Mar}$ \\
\hline Ontario & $17-\mathrm{Mar}$ \\
\hline British Columbia & $18-\mathrm{Mar}$ \\
\hline Newfoundland and Labrador & $18-\mathrm{Mar}$ \\
\hline Northwest Territories & $18-\mathrm{Mar}$ \\
\hline Nunavut & $18-\mathrm{Mar}$ \\
\hline Saskatchewan & $18-\mathrm{Mar}$ \\
\hline Yukon & $18-\mathrm{Mar}$ \\
\hline New Brunswick & $19-\mathrm{Mar}$ \\
\hline Manitoba & $20-\mathrm{Mar}$ \\
\hline Nova Scotia & $22-\mathrm{Mar}$ \\
\hline
\end{tabular}

Note: McCarthy Tetrault, COVID-19: Emergency Measures Tracker, June 18, 2020.

Besides general demographics, most questions of interest in Survey 1 asked participants about the calendar month, media source and language, as well as personal information sharing when they learned of COVID-19 the "first time", which were followed by asking participants to recall their initial perception of the outbreak situation and the likelihood of food shortage in the following two key questions:

- When you first learned of the COVID-19, how likely do you think it will become a serious situation that leads to state of emergency and lock down? Provide your answer in a scale of 1-7 with 7 being the most serious.

- At the start of lock down, how likely do you think there will be a food shortage in the community where you reside? Provide your answer in a scale of 1-7 with 7 being the most likely.

\subsection{Online Survey 2}

The second round of survey was conducted in August 2020. Participants were asked questions regarding the frequency, media source and language, as well as forms of personal contacts taken to obtain and share the updates of COVID-19 related information after 3 months of outbreak and lock down. These were followed by questions exploring participants' shopping frequency, choice of shopping channel (online versus offline), and monetary spending during the outbreak. Consumers' tendency of stockpiling were measured by answers provided to key questions including:

- Do you (or your household) store more food during pandemic than you used to?

- Using the food stocked during this pandemic, my family/ household can survive for about weeks.

314 respondents were collected for Survey 1 with exactly 50-50 split between US and Canadian residents. Respondents for Survey 2 include 151 US residents and 153 Canadian residents.

\section{Empirical Analysis}

\subsection{Survey 1 Data Analysis}

\subsubsection{Information Acquisition at the Beginning of Outbreak}

Although the initial outbreak on the other side of world occurred between November to December 2019, responses from survey 1 indicate that the average American or Canadian learned of COVID-19 the first time in between December 2019 to January 2020. Figure 8 illustrates the distribution of media source from which a US versus Canadian resident learned of COVID-19 the very first time. 


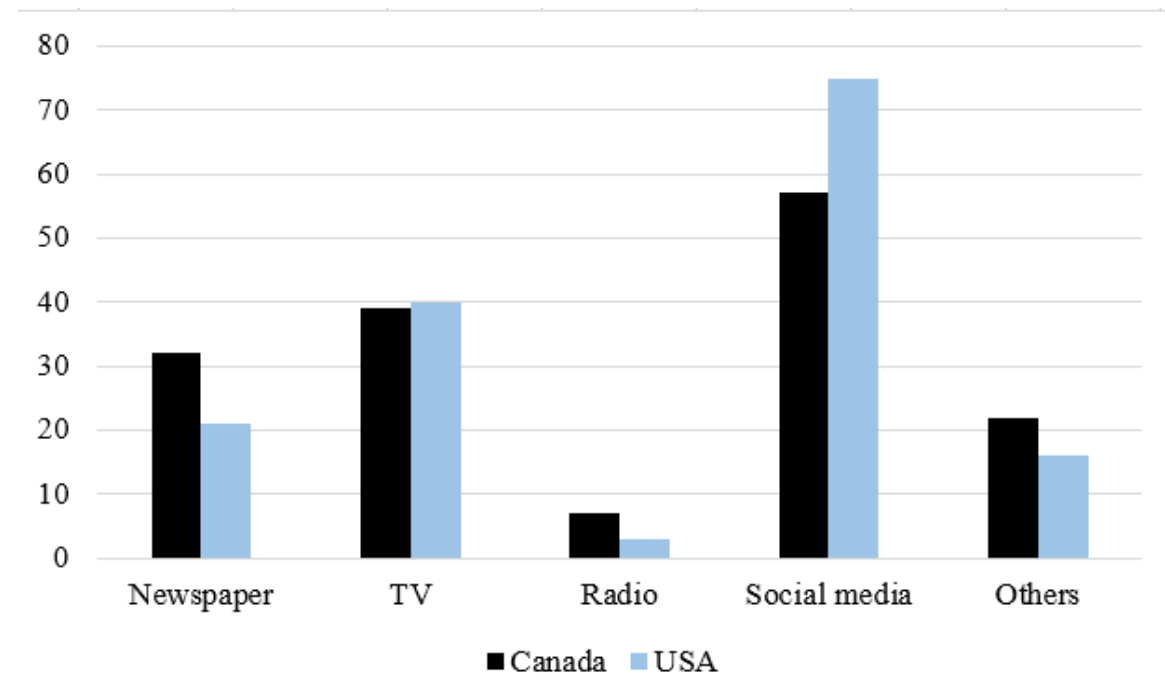

Figure 8. Media Source from which a survey 1 participant learned of COVID-19 the first time

For survey participants in both countries, social media and TV were the top two media sources from which they initially learned of COVID-19. A big contrast between these two countries is that, over 20\% (32 out of 157) Canadian participants learned of COVID-19 the first time from newspapers, which is statistically significant $(\mathrm{P}<0.05$, one-tailed) and greater than the portion (13\%) from American participants. Data collected by Survey 1 also suggests two other differences between US and Canadian participants regarding the initial learning of COVID-19 related news. Over 10\% of respondents in Canada learned of COVID-19 the first time from non-English media report, for American respondents the proportion is $7 \%$ with the difference being marginally significant $(\mathrm{P}<0.1$, one-tailed). Such difference could be attributed to the fact that both English and French are the official languages in Canada. However, $11 \%$ of respondents in Canada stated that their "initial learning of COVID-19 also includes information passed on to me by people from countries outside my residence." This percentage is much higher than that of American respondents (4\%) with the difference being highly significant $(\mathrm{P}<0.01$, one-tailed). Considering the almost 2 months of "information accumulation" (from initial outbreak on the other side of the world to the first time an American or Canadian resident learned of COVID-19), we are interested to see if this particular channel of information acquisition would have significant impact on consumers' initial perception of the outbreak situation.

\subsubsection{Statistical Analysis Using Survey 1 Data}

An F-Test indicates that there is much higher variance (4.1 out of 7) in U.S. respondents' initial assessment on the seriousness of the pandemic situation than from the Canadian residents (2.7 out of 7) with the difference being highly significant $((\mathrm{P}<0.01$, one-tailed $)$. To explore the factors leading to such huge difference in the initial situation assessment between samples from the two countries, a binary logistic regression (Wooldridge, 2010) model is employed to investigate the impacts of media sources and languages on consumers' initial perception of the pandemic situation. The dependent variable Concern $n_{\mathrm{i}}=1$ if a respondent $i$ 's (7-pt scale) rating on the perceived seriousness of the pandemic when first learned of COVID-19 is greater than the sample median $(=3),=0$ otherwise. The list of independent variables include a time variable indexing the month when a respondent first learned of COVID-19, along with a series of dummy variables indicating the media source, language and country origin from which a respondent first learned of COVID-19. Rumbaut (2004) classifies Chinese-Canadian as first-generation, $1 \frac{1}{1} / 2$ generation, or second-generation according to own or parent's birth country and/ or the age when an individual immigrated to Canada. As there is no sufficient respondents belonging to each subcategory defined similarly as in Rumbaut (2004), we created a composite dummy variable Immigrant $_{\mathrm{i}}=1$ if a respondent (or at least one of the parents) was born outside the current country of residence (USA or Canada for the corresponding survey participants), $=0$ otherwise. Table 2 provides full definitions of the variables used in the model estimation, and Table 3 reports the summary statistics. 
Table 2. List of variables for statistical analysis using survey 1 data

\begin{tabular}{|ll|}
\hline Variables & Description \& Values \\
\hline Perceived Seriousness & (7-pt scale) with 1 being "not serious at all", 7 being "most serious" \\
\hline FT & First time learned of COVID-19. 0="Nov,19", 1="Dec,19", 2="Jan,20", 3="Feb,20", 4="Mar,20" \\
\hline Newspaper & 1 if first learned of COVID-19 from online or offline Newspaper; \\
& $=0$ otherwise \\
TV & $=1$ if first learned of COVID-19 from a TV network; \\
& $=0$ otherwise \\
SocialMedia & $=1$ if first learned of COVID-19 from social media; \\
& $=0$ otherwise \\
NonEng & $=1$ if first learned of COVID-19 from non-English media; \\
\hline & $=0$ otherwise \\
DiffCY & $=1$ if first learned of COVID-19 from outside of current country of residence; \\
\hline Immigrant & $=0$ otherwise \\
\hline
\end{tabular}

Table 3. Descriptive statistics for the list of variables in Table 2

\begin{tabular}{|lccccccccccc|}
\hline Variables & \multicolumn{2}{c}{ Mean } & \multicolumn{2}{c}{ Median } & \multicolumn{2}{c}{ Std. Dev } & & Min & Max \\
\hline & Canada & USA & Canada & USA & Canada & USA & Canada & USA & Canada & USA \\
\hline Perceived Serious & 3.178 & 3.961 & 3 & 4 & 1.649 & 1.964 & 1 & 1 & 7 & 7 \\
\hline FT & 1.981 & 2.071 & 2 & 2 & 0.984 & 1.117 & 0 & 0 & 4 & 4 \\
\hline Newspaper & 0.204 & 0.135 & 0 & 0 & 0.403 & 0.342 & 0 & 0 & 1 & 1 \\
\hline TV & 0.242 & 0.258 & 0 & 0 & 0.428 & 0.438 & 0 & 0 & 1 & 1 \\
\hline Social Media & 0.357 & 0.484 & 0 & 0 & 0.479 & 0.500 & 0 & 0 & 1 & 1 \\
\hline NonEng & 0.108 & 0.071 & 0 & 0 & 0.311 & 0.257 & 0 & 0 & 1 \\
\hline DiffCY & 0.11 & 0.041 & 0 & 0 & 0.312 & 0.197 & 0 & 0 & 1 & 1 \\
\hline Immigrant & 0.293 & 0.146 & 0 & 0 & 0.455 & 0.353 & 0 & 0 & 1 & 1 \\
\hline
\end{tabular}

The probability that a respondent $i$ would perceive the situation to be serious after first learning of COVD-19 is specified as

$$
\operatorname{Pr}\left(\text { Concern }_{i}=1\right)=\frac{\exp \left(x_{i} \beta\right)}{1+\exp \left(x_{i} \beta\right)}
$$

where

$x_{i} \beta=\beta_{0}+\beta_{1} F_{i}+\beta_{2}$ Newspaper $_{i}+\beta_{3} T V_{i}+\beta_{4}$ SocialMedia $_{i}+\beta_{5}$ NonEng $_{i}+\beta_{6}$ DiffCY $_{i}+\beta_{7}$ Immigrant $_{i}$

Full results of estimation are reported in Table 4. For Canadian respondents, the only media source that had statistically significant effect on their initial perception of the situation seriousness is social media with estimated coefficient $\beta_{4}=-1.2$, which can be converted to $\exp \left(\beta_{4}\right)=0.3$. This points to an interesting finding: all else being equal, the odds of perceiving a serious outbreak early are $70 \%$ lower for a Canadian who first learned of 
COVID-19 through social media! In contrast, TV is the only media source that had statistically significant effect on American respondents' initial perception of the outbreak situation with estimated coefficient being 1.068, which can also be converted to the effect on odds ratio: $\exp (1.068)=2.909$. All else being equal, the odds of perceiving a serious outbreak early are 190\% higher for a U.S. resident who first learned of COVID-19 through TV networks. We believe this findings echoes the huge diversification in terms of opinion and coverage view across different TV networks in U.S. According to a survey conducted as a part of Pew Research Center's Election News Pathways project (Jurkowitz \& Mitchell, 2020), the pandemic coverage varies notably across Fox News, MSNBC and CNN (the three major cable news networks featured in the analysis as American's major sources of political and general news). Consequently first learning of COVID-19 from the TV network which reports the pandemic outbreak in much more serious tone (with greater coverage) would drive an American to draw similar conclusion about the situation. For survey respondents from both countries, learning of COVID-19 news the first time from a non-English media source significantly increase the likelihood of perceiving the situation to be serious at the beginning (exponentiated coefficient $=3.7$ for Canadian, $=7.2$ for American). Another significant difference is that Canadian respondents having immigration background (as defined similarly in Cleveland \& Xu, 2019) are more likely to form an early perception of serious outbreak (estimated coefficient $=0.654$, exponentiated coefficient $=1.924$ ) while such effect is insignificant for respondents from the U.S. We also estimated the binary logit model (Equation 1) by including in Equation (2) the interaction terms between Immigrant and different media source variables in Table 2. None of estimated coefficients for the interactive terms is statistically significant. We believe this can be attributed to the fact that the ethnicity backgrounds of Amazon MTurk workers are not sufficiently diversified (Ross, Irani, Silberman, Zaldivar, \& Tomlinson, 2010).

Table 4. Binary Logistic Regression Output using Survey 1 Data

\begin{tabular}{|lllllllll|}
\hline Variables & Parameters & \multicolumn{2}{c}{ Estimated Coefficient } & \multicolumn{2}{c}{ Std. Error } & \multicolumn{2}{c|}{ P-Value } \\
\hline \multirow{2}{*}{ Intercept } & & (Canada) & (USA) & (Canada) & (USA) & (Canada) & (USA) \\
\cline { 2 - 9 } FT & -0.630 & -0.849 & 0.518 & 0.645 & 0.224 & 0.188 \\
\hline Newspaper & $\beta 2$ & 0.184 & 0.059 & 0.187 & 0.163 & 0.327 & 0.718 \\
\hline TV & $\beta 3$ & -0.748 & 1.044 & 0.549 & 0.721 & 0.173 & 0.147 \\
\hline SocialMedia & $\beta 4$ & -0.555 & 1.068 & 0.525 & 0.647 & 0.291 & $0.099^{*}$ \\
\hline NonEng & $\beta 5$ & -1.200 & 0.958 & 0.515 & 0.608 & $0.020^{*}$ & 0.115 \\
\hline DiffCY & $\beta 6$ & 1.315 & 1.974 & 0.574 & 1.105 & $0.022^{*}$ & $0.074 *$ \\
\hline Immigrant & $\beta 7$ & 0.620 & -1.564 & 0.589 & 1.095 & 0.293 & 0.153 \\
\hline Note: & 0.654 & 0.770 & 0.414 & 0.564 & $0.104 *$ & 0.173 \\
\hline
\end{tabular}

Note: * indicates statistically significance at alpha level of 0.1 or less.

\subsection{Survey 2 Data Analysis}

\subsubsection{Information Acquisition during Lockdown}

Responses collected by Survey 2 continue showing difference in terms of information gathering and exchange after about three months of outbreak between U.S. and Canadian participants. As illustrated by Figure 9, the percentage of Canadians who checked COVID-19 news in more than one languages is almost twice as much as that of Americans, such difference is found to be statistically significant $(\mathrm{P}<0.001$, one-tailed). 


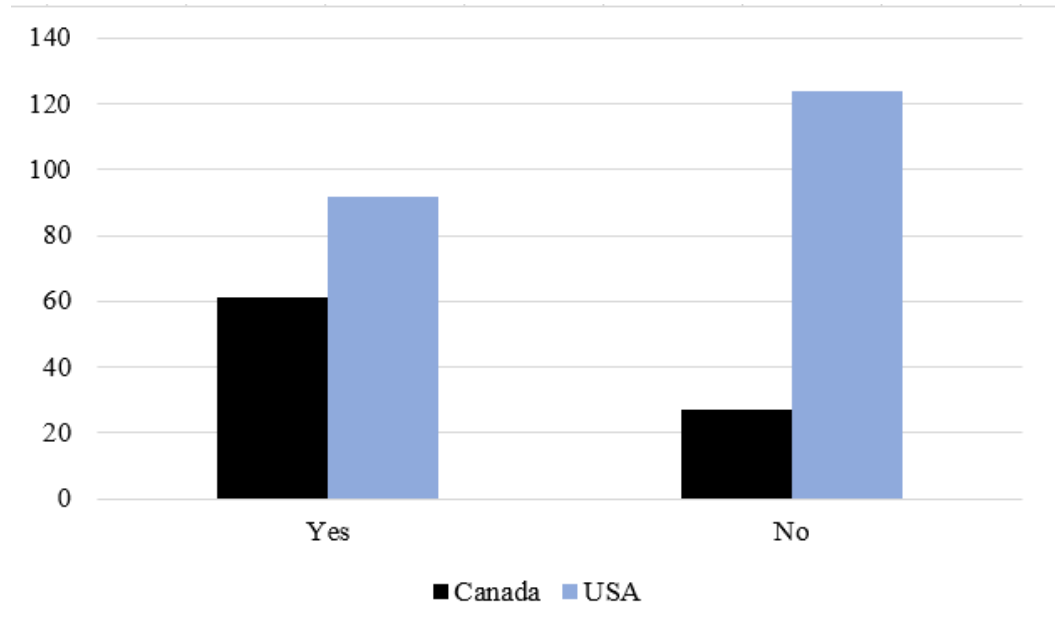

Figure 9. Number of survey 2 participants who browsed COVID-19 news in more than one language

Over $80 \%$ of participants from either country have been discussing and sharing COVID-19 related information (e.g. cases, social distancing, food stocking) with others through multiple channels including inside family residence, colleagues at work, family or friends from the same or different city/provinces, etc. A big contrast is, over $41 \%$ of respondents from Canada have been exchanging information with people outside their country of residence, while this percentage is only about $12 \%$ among respondents from U.S. The difference is again statistically significant ( $\mathrm{P}<0.001$, one-tailed test). Respondents were also asked to state their level of satisfactions towards government public's health advisories, pandemic-relief social benefits, as well as their concerns about job security during the outbreak. Respondents from Canada are more satisfied with government's public health advisory (median $=3.7$ out of 5-pt scale) than US participants (median $=2.5$ out of 5-pt scale). Similar pattern is found on the survey respondents' satisfaction level towards government's pandemic-relief social benefits (median $=3.5$ for Canadian participants which is greater than median $=2.5$ for U.S. participants, out of 5-pt scale). Meanwhile Canadians are found to be more concerned (median $=4.4$ out of 7 -pt scale) in comparison to the Americans (median $=3.5$ out of 7-pt scale) about job security. All the above differences between survey responses from the two countries are statistically significant $(\mathrm{P}<0.001$, one-tailed test).

\subsubsection{Statistical Analysis Using Survey 2 Data}

Another binary logistic regression model is employed to investigate factors influencing consumers' propensity of stockpiling food during COVID-19 outbreak. The dependent variable Stocking $\mathrm{i}_{\mathrm{i}}=1$ if a respondent $i$ answered "Yes" to question in survey 2 stating that the household stocked more food during pandemic than it used to, $=0$ otherwise. The list of independent variables include media language selection, shopping frequency, percentage of online shopping, job security concern, plus immigration status (using the same definition as in survey 1) along with other demographic characteristics. Table 5 provides full definitions of the variables used in the survey 2 model estimation, and Table 6 reports the summary statistics. 
Table 5. List of variables for statistical analysis using survey 2 data

\begin{tabular}{|ll|}
\hline Variables & Description \& Values \\
\hline Stocking & $=1$ if household stocks more food during outbreak than it used to; \\
\hline & $=1$ otherwise \\
Languages & $=0$ otherwise \\
\hline & Offline shopping frequency. 0="Pure online", 1="Once a month", 2="Once every 2 weeks", 3="Once every \\
Frequency & week", 4="More than once per Week" \\
\hline Online & Percentage of online grocery shopping during the pandemic \\
\hline Job & (7-pt scale) with 1 being "not concerned at all", 7 being "very concerned" about job security during outbreak \\
\hline Immigrant & $=1$ respondent or at least one parent was born outside current country of residence; \\
\hline Gender & $=1$ otherwise \\
\hline Caucasian & $=1$ if self-identified as this ethnicity group; =0 otherwise \\
\hline
\end{tabular}

Table 6. Descriptive statistics for the list of variables in Table 5

\begin{tabular}{|llllllllllll|}
\hline Variables & \multicolumn{2}{c}{ Mean } & \multicolumn{2}{c}{ Median } & \multicolumn{2}{c}{ Std. Dev } & \multicolumn{2}{c}{ Min } & \multicolumn{2}{c|}{ Max } \\
\hline & Canada & USA & Canada & USA & Canada & USA & Canada & USA & Canada & USA \\
\hline Stocking & 0.601 & 0.636 & 1 & 1 & 0.490 & 0.481 & 0 & 0 & 1 & 1 \\
\hline Languages & 0.399 & 0.179 & 0 & 0 & 0.490 & 0.383 & 0 & 0 & 1 & 1 \\
\hline Frequency & 2.803 & 2.535 & 3 & 3 & 1.464 & 1.336 & 0 & 0 & 9 & 9 \\
\hline Online & 0.302 & 0.341 & 0.2 & 0.2 & 0.322 & 0.350 & 0 & 0 & 1 & 1 \\
\hline Job & 4.353 & 3.536 & 5 & 4 & 1.949 & 1.833 & 1 & 1 & 7 & 7 \\
\hline Immigrant & 0.316 & 0.079 & 0 & 0 & 0.465 & 0.270 & 0 & 0 & 1 & 1 \\
\hline Gender & 0.480 & 0.490 & 0 & 0 & 0.501 & 0.502 & 0 & 0 & 1 & 1 \\
\hline Caucasian & 0.546 & 0.815 & 1 & 1 & 0.500 & 0.390 & 0 & 0 & 1 & 1 \\
\hline
\end{tabular}

The probability that a respondent $i$ would engage in food stockpiling during the outbreak is specified as

$$
\operatorname{Pr}\left(\text { Stocking }_{i}=1\right)=\frac{\exp \left(x_{i} \gamma\right)}{1+\exp \left(x_{i} \gamma\right)}
$$

where

$$
\begin{gathered}
x_{i} \gamma=\gamma_{0}+\gamma_{1} \text { Languages }_{i}+\gamma_{2} \text { Frequency }_{i}+\gamma_{3} \text { Online }_{i}+\gamma_{4} \text { Job }_{i}+\gamma_{5} \text { Immigrant }_{i}+\gamma_{6} \text { Gender }_{i} \\
+\gamma_{7} \text { Caucasian }_{i}
\end{gathered}
$$

According to the full estimation output reported in Table 7, responses to survey 2 revealed much bigger behavioural difference between Canada and U. S. customers after passing the initial outbreak period. The only common factor which significantly affects the propensity of food stocking in both countries is the concern for job security. The estimated coefficients $\left(\gamma_{4}\right)$ are 0.353 for Canadian respondents and 0.332 for U.S. respondents, both of which can be converted to the exponentiated level around 1.4. Thus all else being equal, the odds of food stocking are $40 \%$ higher for a (U.S. or Canadian) customer who is more concerned about job security during the pandemic. We believe this finding has important economic policy implication during the pandemic. It was found in survey 1 that first learning of COVID-19 in non-English media significantly affects a consumer (either in U.S. or Canada)'s initial perception regarding the seriousness of this pandemic. We found in survey 2 that similar effect continues influencing a Canadian customer's decision to stockpiling food during the outbreak. The estimated coefficient of $\gamma_{1}$ equals 0.878 for Canadian respondents, which suggests a huge quantitative effect as 
$\exp \left(\gamma_{1}\right)=2.407$ : all else being equal, the odds of food stocking are $140 \%$ higher for a Canadian resident who has been following COVID-19 news in multiple languages during the outbreak. Canadians who conducted greater proportion of grocery shopping online are also more likely to stockpiling food, while the effect of offline shopping frequency goes the other direction. Caucasian customers in Canada are found to be less likely of food stocking. Yet none of these factors has statistically significant impact on American customers' food stockpiling decision. Data from U.S. respondents only suggested that female customers are less likely to stockpiling.

Table 7. Binary Logistic Regression Output using Survey 2 Data

\begin{tabular}{|llllllll|}
\hline Variables & Parameters & \multicolumn{2}{c}{ Estimated Coefficient } & \multicolumn{2}{c}{ Std. Error } & \multicolumn{2}{c|}{ P-Value } \\
\hline & & $($ Canada $)$ & (USA) & (Canada) & (USA) & (Canada) & (USA) \\
\hline Intercept & $\Upsilon_{0}$ & -0.509 & -0.924 & 0.867 & 0.733 & 0.557 & 0.208 \\
\hline Languages & $\Upsilon_{1}$ & 0.878 & 0.790 & 0.441 & 0.593 & $0.047 *$ & 0.182 \\
\hline Frequency & $\Upsilon_{2}$ & -0.319 & 0.165 & 0.163 & 0.162 & $0.050^{*}$ & 0.308 \\
\hline Online & $\Upsilon_{3}$ & 1.295 & 0.512 & 0.712 & 0.580 & $0.069 *$ & 0.377 \\
\hline Job & $\Upsilon_{4}$ & 0.353 & 0.332 & 0.114 & 0.113 & $0.002^{*}$ & $0.003 *$ \\
\hline Immigrant & $\Upsilon_{5}$ & -0.575 & -0.071 & 0.512 & 0.855 & 0.262 & 0.933 \\
\hline Gender & $\Upsilon_{6}$ & 0.491 & -1.179 & 0.419 & 0.398 & 0.241 & $0.003 *$ \\
\hline Caucasian & $\Upsilon_{7}$ & -0.765 & 0.418 & 0.448 & 0.541 & $0.088^{*}$ & 0.440 \\
\hline
\end{tabular}

Note: * indicates statistically significance at alpha level of 0.1 or less.

\section{Conclusion}

\subsection{Summary of Research Findings}

Despite near $100 \%$ reach of internet in both countries, Hypothesis \#1 is only found to be supported by Canadian participants' responses to survey 1 . Social media is the only media source of initial COVID-19 information which significantly affects the likelihood of a Canadian perceiving the situation to be serious at the beginning of outbreak. Such effect was not found from U.S participants in survey 1. Hypothesis \#2 was supported by estimation results using survey 1 data from both U.S. and Canadian participants. First learning of COVID-19 from non-English media report significantly increases the likelihood of a consumer having early perception of a serious outbreak. As both countries under our study have another language other than English to be official or popular language (French in Canada, Spanish in U.S.), we tried to seek additional support to this hypothesis from the "outside country of residence" information source. Due to the small proportion of respondents (Canada 11\%, U.S. 4\% as in Table 3) that fall into the classification in survey 1, first learning COVID-19 from outside country of residence was not found to be a significant factor influencing a consumer's initial perception of the outbreak to be serious. We did find that a Canadian who has stronger immigrant background as defined in Table 1 is more likely to perceive the pandemic to be serious at the beginning of outbreak, which could be considered as additional support to Hypothesis \#2.

Hypothesis \#3 did not receive much support from analyzing participants' responses to survey 2. In this round of survey, participants were asked again if they have been following and exchange COVID-19 related information via multiple media types, media reports in different languages, and especially with people outside participants' country of residences. None of these factors were found to significantly influence a (U.S. or Canada) consumer's propensity to food stockpiling. Neither is a participant's immigration background affects the stockpiling decision. The only exception is that following COVID-19 news in multiple languages would increase the likelihood of a consumer in Canada to engage in food stocking. Participants were also asked to state their opinion (concern or satisfaction) towards multiple social-economic issues related to COVID-19: government official's public health advisory, pandemic relief social benefit, job security concern during the outbreak, and the social behaviour norm post pandemic. Only the concern for job security is found to have significant effect on increasing the likelihood that a participant (U.S. or Canada) would engage in food stockpiling during the pandemic. We believe this finding provides support to hypothesis \#4. 


\subsection{Limitations and Future Researches}

Although Mechanical Turk workers are more diverse than the undergraduate student subject pool, it is however significantly less diverse than the general US or Canadian population (Hitlin, 2016). Figure 10 illustrates the birth decades of Canadian participants in survey 1 , which were significantly younger and the pattern was similar for U.S. participants. The high percentage of Caucasian participants in survey 2 (55\% in Canada, $82 \%$ in U.S. according to Table 2) also suggest less ethnicity diversification.

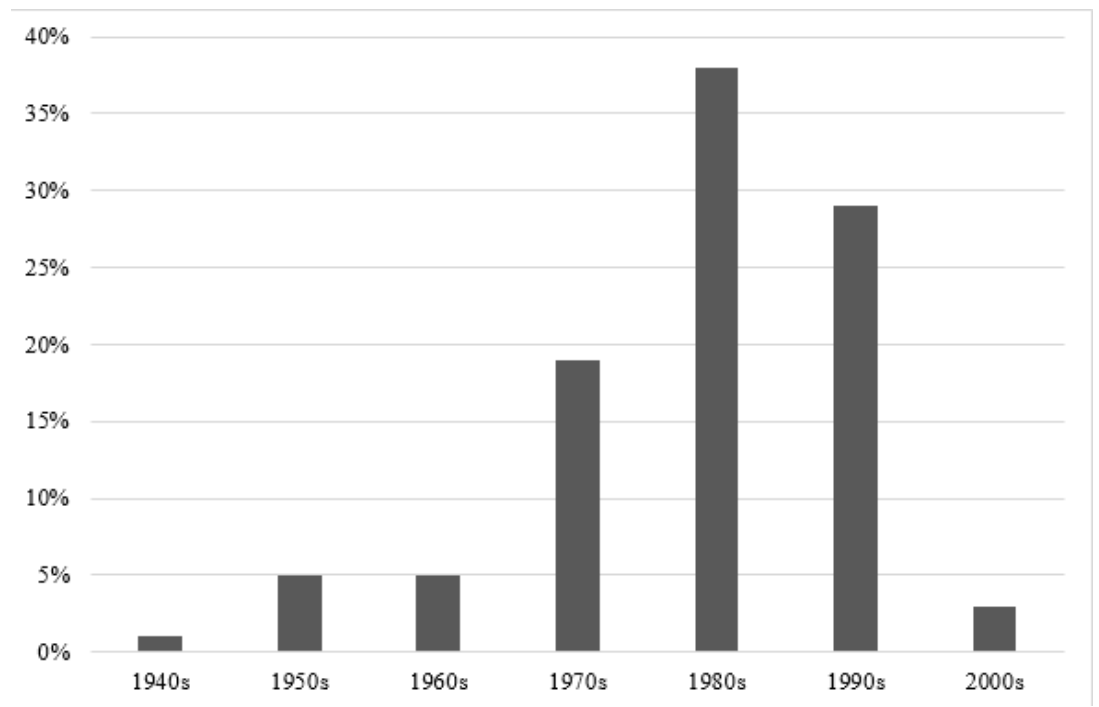

Figure 10. Birth decades of Canadian MTurk participants for survey 1

Even with such participant profile we are still able to identify some significant factors influencing consumer behaviour under such unprecedented pandemic outbreak. However we believe this presents a major challenge to our research question regarding consumers' information acquisition and exchange regarding COVID-19 through multiple sources that are tied specifically to their ethnicity backgrounds. Surveying from a more diversified subject pool is certainly an important direction of future research in order to obtain a more comprehensive understanding on how the ethnicity-related factors (Laroche, Kim, \& Clarke, 1997) affect consumers' information processing and stockpiling behaviour under such a global pandemic.

The current paper focuses on the comparison between U.S. and Canadian consumers under the pandemic outbreak. Greater resources including time, funding and human capitals could allow us to expand the scope of primary data collection by covering more countries over different continents. For example, it would be interesting to conduct similar comparison between consumers from Europe such as U.K, Italy, versus those from Asia or Oceania (e.g. Australia). Larger data size across multiple countries/ regions could also allow the employment of more advanced statistical models (e.g. structural equation models, SEM) for validity and reliability of the empirical investigations. Findings from those future research directions, in combined with insights collected from the current paper, would help weave a complete "map" to fully understand the short term as well as long term influences of COVID-19 (beginning, during and post outbreak) on consumers' information acquisition and shopping behaviour.

\section{Acknowledgments}

The survey studies reported in this manuscript are sponsored by University of Guelph COVID-19 Research Development and Catalyst Fund awarded in May 2020.

\section{References}

Assuncao, J. L., \& Meyer, R. J. (1993). The rational effect of price promotions on sales and consumption. Management Science, 39(5), 517-535. https://doi.org/10.1287/mnsc.39.5.517

Azadegan, A., Patel, P. C., Zangoueinezhad, A., \& Linderman, K. (2013), The effect of environmental complexity and environmental dynamism on lean practices. Journal of Operations Management, 31(4), 193-212. https://doi.org/10.1016/j.jom.2013.03.002

Barello, S. H. (2014). Consumer spending and US employment from the 2007-2009 recession through 2022. 
Monthly Labor Review, 137(10), 1-36. https://doi.org/10.21916/mlr.2014.34

Bell, D. R., Chiang, J., \& Padmanabhan, V. (1999). The decomposition of promotional response: An empirical generalization. Marketing Science, 18(4), 504-526. https://doi.org/10.1287/mksc.18.4.504

Bendoly, E., \& Hur, D. (2007). Bipolarity in reactions to operational 'constraints': OM bugs under an OB lens. Journal of Operations Management, 25(1), 1-13. https://doi.org/10.1016/j.jom.2005.08.004

Besson, E. K. (2020). COVID-19 (Coronavirus): Panic buying and its impact on global health supply chains. World Bank. Retrieved from

https://blogs.worldbank.org/health/covid-19-coronavirus-panic-buying-and-its-impact-global-health-supplychains

Blattberg, R. C., Eppen, G. D., \& Lieberman, J. (1981). A theoretical and empirical evaluation of price deals for consumer nondurables. Journal of Marketing, 45(1), 116-129. https://doi.org/10.1177/002224298104500111

Bogart, N. (2020). Nobody was ready': Retail Council of Canada urges consumers to stop panicking as grocers stripped bare. CTV news. Retrieved from

https://www.ctvnews.ca/health/coronavirus/nobody-was-ready-retail-council-of-canada-urges-consumers-to -stop-panicking-as-grocers-stripped-bare-1.4851901

Boizot, C., Robin, J. M., \& Visser, M. (2001). The demand for food products: an analysis of interpurchase times and purchased quantities. The Economic Journal, 111(470), 391-419. https://doi.org/10.1111/1468-0297.00613

Breiter, A., \& Huchzermeier, A. (2015). Promotion planning and supply chain contracting in a high-low pricing environment. Production and Operations Management, 24(2), 219-236. https://doi.org/10.1111/poms. 12250

Charlton, E. (2020). How experts are fighting the Coronavirus 'infodemic'. World Economic Forum. Retrieved from https://www.weforum.org/agenda/2020/03/how-experts-are-fighting-the-coronavirus-infodemic/

Chen, Y., Rajabifard, A., Sabri, S., Potts, K. E., Laylavi, F., Xie, Y., \& Zhang, Y. (2020). A discussion of irrational stockpiling behaviour during crisis. Journal of Safety Science and Resilience, 1(1), 57-58. https://doi.org/10.1016/j.jnlssr.2020.06.003

Cleveland, M., \& Xu, C. (2019). Multifaceted acculturation in multiethnic settings. Journal of Business Research, 103, 250-260. https://doi.org/10.1016/j.jbusres.2019.01.051

Easley, D., \& Kleinberg, J. (2010). Networks, crowds, and markets reasoning about a highly connected world. New York, NY: Cambridge University Press.

El-Assal, K. (2020). Over $80 \%$ of Canada's population growth from immigration. CIC news. Retrieved from https://www.cicnews.com/2020/06/over-80-of-canadas-population-growth-from-immigration-0614770.html

Elmore, C. (2017). Irma: Frenzied buying in Palm Beach, St. Lucie regions led state. The Palm Beach Post. Retrieved from https://www.palmbeachpost.com/business/data-firm-tracked-how-hurricane-irma-storesales-boomed-went-b ust/LIDVXIL3qlqJGLlaosfSiL/

Gupta, S. (1988). Impact of sales promotions on when, what, and how much to buy. Journal of Marketing Research, 25(4), 342-355. https://doi.org/10.1177/002224378802500402

Helsen, K., \& Schmittlein, D. C. (1992). Some characterizations of stockpiling behavior under uncertainty. Marketing Letters, 3, 5-16. https://doi.org/10.1007/BF00994076

Hendel, I., \& Nevo, A. (2006). Measuring the implications of sales and consumer inventory behavior. Econometrica, 74(6), 1637-1673. https://doi.org/10.1111/j.1468-0262.2006.00721.x

Hendricks, K. B., Jacobs, B. W., \& Singhal, V. R. (2019). Stock market reaction to supply chain disruptions from the 2011 Great East Japan Earthquake. Manufacturing \& Service Operations Management, 22(4), 683-699. https://doi.org/10.1287/msom.2019.0777

Hitlin, P. (2016). Research in the Crowdsourcing Age, a Case Study. Pew Research Center. Retrieved from http://www.pewinternet.org/2016/07/11/research-in-the-crowdsourcing-age-a-case-study/

Ho, T. H., Tang, C. S., \& Bell, D. R. (1998). Rational shopping behavior and the option value of variable pricing. Management Science, 44(12), 145-160. https://doi.org/10.1287/mnsc.44.12.S145

Hobson, C. J., Kamen, J., Szostek, J., Nethercut, C. M., Tiedmann, J. W., \& Wojnarowicz, S. (1998). Stressful 
life events: A revision and update of the Social Readjustment Rating Scale. International Journal of Stress Management, 5(1), 1-23. https://doi.org/10.1023/A:1022978019315

Huchzermeier, A., Iyer, A., \& Freiheit, J. (2002). The supply chain impact of smart customers in a promotional environment. Manufacturing \& Service Operations Management, 4(3), 228-240. https://doi.org/10.1287/msom.4.3.228.7755

Iyer, A. V., \& Ye, J. (2000). Assessing the value of information sharing in a promotional retail environment. Manufacturing \& Service Operations Management, 2(2), 128-143. https://doi.org/10.1287/msom.2.2.128.12350

Jurkowitz, M., \& Mitchell, A. (2020). Cable TV and COVID-19: How Americans perceive the outbreak and view media coverage differ by main news source. Pew Research Center. Retrieved from https://www.journalism.org/2020/04/01/cable-tv-and-covid-19-how-americans-perceive-the-outbreak-and-v iew-media-coverage-differ-by-main-news-source/

Laroche, M., Kim, C. K., \& Clarke, M. (1997). The effects of ethnicity factors on consumer deal interests: An empirical study of French-and English-Canadians. Journal of Marketing Theory and Practice, 5(1), 100-112. https://doi.org/10.1080/10696679.1997.11501754

Loxton, M., Truskett, R., Scarf, B., Sindone, L., Baldry, G., \& Zhao, Y. (2020). Consumer behaviour during crises: preliminary research on how coronavirus has manifested consumer panic buying, herd mentality, changing discretionary spending and the role of the media in influencing behaviour. Journal of Risk and Financial Management, 13(8), 166-187. https://doi.org/10.3390/jrfm13080166

Rocca, R. (2020). Ontario reopening Stage 3: Gathering limit increasing as indoor dining, gyms permitted to reopen. Global News. Retrieved from https://globalnews.ca/news/7169242/ontario-coronavirus-stage-3-reopening-plan/

Ross, J., Irani, L., Silberman, M. S., Zaldivar, A., \& Tomlinson, B. (2010). Who are the crowdworkers? Shifting demographics in Mechanical Turk. CHI'10 extended abstracts on Human factors in computing systems, 2863-2872. https://doi.org/10.1145/1753846.1753873

Rumbaut, R. G. (2004). Ages, life stages, and generational cohorts: decomposing the immigrant first and second generations in the United States. International Migration Review, 38(3), 1160-1205. https://doi.org/10.1111/j.1747-7379.2004.tb00232.x

Scamman, K. (2019). Immigration Trends and Language Diversity in the United States (Infographic). Telelanguage.com. Retrieved from https://telelanguage.com/immigration-trends-and-language-diversity-in-the-united-states-infographic/

Shapira, D., Coco, J., \& Sorbara, T. (2020). Canada: Impacts Of COVID-19 On Landlord And Tenant Obligations In Commercial Leases. Wildeboer Dellelce LLP. Retrieved from

https://www.mondaq.com/canada/litigation-contracts-and-force-majeure/927008/impacts-of-covid-19-on-la ndlord-and-tenant-obligations-in-commercial-leases

Snyder, L. V., Atan, Z., Peng, P., Rong, Y., Schmitt, A. J., \& Sinsoysal, B. (2015). OR/MS models for supply chain disruptions: A review. IIE Transactions, 48(2), 89-109. https://doi.org/10.1080/0740817X.2015.1067735

Sterman, J. D., \& Dogan, G. (2015). "I'm not hoarding, I'm just stocking up before the hoarders get here.": Behavioral causes of phantom ordering in supply chains. Journal of Operations Management, 39-40, 6-22. https://doi.org/10.1016/j.jom.2015.07.002

Sweeny, K., \& Shepperd, J. A. (2007). Do people brace sensibly? Risk judgments and risk prevalence. Personality and Social Psychology Bulletin, 33(8), 1064-1075. https://doi.org/10.1177/0146167207301024

Tokar, T., Aloysius, J., Williams, B., \& Waller, M. (2014). Bracing for demand shocks: An experimental investigation. Journal of Operations Management, 32(4), 205-216. https://doi.org/10.1016/j.jom.2013.08.001

Wernerfelt, B., \& Karnani, A. (1987). Competitive strategy under uncertainty. Strategic Management Journal, 8(2), 187-194. https://doi.org/10.1002/smj.4250080209

Wooldridge, J. M. (2010). Econometric analysis of cross section and panel data. Cambridge, MA: MIT press.

Yuen, K. F., Wang, X., Ma, F., \& Li, K. X. (2020). The psychological causes of panic buying following a health crisis. International Journal of Environmental Research and Public Health, 17(10), 3513. 
https://doi.org/10.3390/ijerph17103513

Zheng, R., Shou, B., \& Yang, J. (2020). Supply disruption management under consumer panic buying and social learning effects. Omega, 102238. https://doi.org/10.1016/j.omega.2020.102238

Zhuang, H., Leszczyc, P. T. P., \& Lin, Y. (2018). Why is price dispersion higher online than offline? The impact of retailer type and shopping risk on price dispersion. Journal of Retailing, 94(2), 136-153. https://doi.org/10.1016/j.jretai.2018.01.003

\section{Copyrights}

Copyright for this article is retained by the author(s), with first publication rights granted to the journal.

This is an open-access article distributed under the terms and conditions of the Creative Commons Attribution license (http://creativecommons.org/licenses/by/4.0/). 